\title{
RESEARCH
}

Open Access

\section{High burden of undernutrition among primary school-aged children and its determinant factors in Ethiopia; a systematic review and meta-analysis}

Moges Agazhe Assemie ${ }^{1 *}$ (D) Alehegn Aderaw Alamneh², Daniel Bekele Ketema ${ }^{1}$, Ali Mekonen Adem³, Melaku Desta ${ }^{4}$, Pammla Petrucka ${ }^{5,6}$ and Mekdes Marew Ambaw ${ }^{7}$

\begin{abstract}
Background: Undernutrition remains a major public health concern affecting both children and adolescents in Ethiopia. However, little attention has been given to the undernutrition of primary school-aged children, with their exclusion within national surveys. Therefore, this systematic review and meta-analysis was conducted to determine pooled estimate and determinant factors of undernutrition among primary school-aged children (6 to 15 years of age) in Ethiopia.
\end{abstract}

Method: We systematically retrieved available articles on the prevalence of undernutrition in primary school-aged children in Ethiopia by using a number of computerized databases, including PubMed, Scopus, Cochrane Library, Google Scholar, and Science Direct between September 1 and November 25, 2019. Two authors independently extracted relevant data using a standardized data extraction form. Heterogeneity among included studies was assessed with the Cochrane $\mathrm{Q}$ test statistics and Higgins $P^{2}$ tests. The pooled estimates and determinant factors of school-aged undernutrition were assessed with random-effects model using Stata/se Version 14.

Result: We have retrieved 30 eligible articles with pooled sample size of 16,642 primary school- aged children to determine the prevalence of undernutrition in Ethiopia. Hence, the pooled prevalence of stunting, underweight, and wasting were found to be $21.3 \%$ (95\% Cl: 17.0, 25.5), $18.2 \%$ (95\% Cl: 14.4, 22.0) and $17.7 \%(95 \% \mathrm{Cl}, 13.5,21.8)$ respectively. Heterogeneity was assessed by doing subgroup analysis for study province/region. Thus, the highest prevalence of stunting was $27.6 \%(95 \% \mathrm{Cl}, 20.7,34.5)$ and underweight $22.7 \%(95 \% \mathrm{Cl}, 19.2,26.3)$ in Amhara Region while, in the instance of wasting, it was $19.3 \%(95 \%$ Cl: $5.1,33.4)$ in Southern Nations, Nationalities and People's Region. Maternal educational status $(\mathrm{OR}=1.91,95 \% \mathrm{Cl}: 1.33,2.73)$, age of school-aged child $(\mathrm{OR}=0.56,95 \% \mathrm{Cl}$ : 0.44 , 0.72 ) and sex of school-aged child $(\mathrm{OR}=0.73,95 \% \mathrm{Cl}: 0.62,0.85)$ were found to be significantly associated with stunting. Maternal educational status $(\mathrm{OR}=0.6,95 \% \mathrm{Cl}: 0.36,0.9)$ and age of school-aged child $(\mathrm{OR}=2.74,95 \% \mathrm{Cl}$ : $1.81,4.14)$ were associated with thinness/wasting. Parasitic infection $(\mathrm{OR}=2.02,95 \% \mathrm{Cl}: 1.10,3.73)$ were associated with underweight of school age children.

(Continued on next page)

\footnotetext{
*Correspondence: agazhemoges@gmail.com

'Biostatstics Unit, Department of Public Health, College of Health Science, Debre Markos University, P.O. Box: 269, Debre Markos, Ethiopia

Full list of author information is available at the end of the article
}

(c) The Author(s). 2020, corrected publication. 2020. Open Access This article is licensed under a Creative Commons Attribution 4.0 International License, which permits use, sharing, adaptation, distribution and reproduction in any medium or format, as long as you give appropriate credit to the original author(s) and the source, provide a link to the Creative Commons licence, and indicate if changes were made. The images or other third party material in this article are included in the article's Creative Commons licence, unless indicated otherwise in a credit line to the material. If material is not included in the article's Creative Commons licence and your intended use is not permitted by statutory regulation or exceeds the permitted use, you will need to obtain permission directly from the copyright holder. To view a copy of this licence, visit http://creativecommons.org/licenses/by/4.0/. The Creative Commons Public Domain Dedication waiver (http:// creativecommons.org/publicdomain/zero/1.0/) applies to the data made available in this article, unless otherwise stated in a credit line to the data. 


\begin{abstract}
(Continued from previous page)
Conclusion: The prevalence of stunting and underweight among primary school-aged children are moderately high while acute undernutrition (wasting) is more critical than under-five national average as reported in the 2016 Ethiopian Demography and Health Survey. Therefore, this finding warrants the need to design a school-aged children nutrition survey and expand school feeding programs to improve the nutritional status of primary schoolaged children in the country. In addition, emphasis should be given to female school-aged children in the early school years, creating awareness for those mothers who lack formal education, and preventing and treating/ deworming parasitic infection. Moreover, researchers must conduct research in province/regions which have not yet studied school aged children's nutritional status to date.
\end{abstract}

Keywords: Undernutrition, Primary school-aged children, Stunting, Underweight, Thinness/wasting, Ethiopia

\section{Background}

Child nutrition is an index and prerequisite for the national investment in the development of a nation's future social capital; therefore, ensuring optimal child growth and development is important to accelerate economic development of nations $[1,2]$. Undernutrition continues to be a primary cause of disease susceptibility, morbidity, and mortality among school-aged children particularly in resource limited countries which globally accounts for half of all deaths in this cohort $[3,4]$. Undernutrition is caused by a lack or imbalance of nutrients in the body. It includes stunting, wasting, and underweight which is a consequence of consuming too few essential nutrients or excreting them more rapidly than they can be replaced [5].

Globally, more than 200 million school-aged children are stunted and underweight which contributes to 2.2 million deaths annually [4]. If an interventional action is not taken, the cognitive and physical impairment will increase to one billion by 2020 [6-8]. Like under-five children, school-aged children are among the most vulnerable segments of the population to undernutrition in Sub-Saharan Africa [6, 9]. Undernutrition among school-aged children results in poor cognitive development, lower school performance, reduced body size, reduced muscular strength, and depleted work capacity $[8,10-13]$.

Primary school-aged children who are undernourished can exhibit improvement in their growth and development if their environment improves [14-16]. Hence, special attention to proper nutritional surveys or suitable nutritional intervention programmes in a community can provide the baseline upon which to assess the occurrence of undernutrition among primary school-aged children [17]. Therefore, targeted interventions in primary schoolaged children can help to complement efforts in the preschool years and can reduce the perpetuation of undernutrition and its effects on health [12].

Therefore, we conducted this systematic review and meta-analysis to bridge the data inconsistencies and gaps in the existing evidence regarding nationally representative undernutrition among primary school-aged children in Ethiopia. This finding will help decision makers and other concerned stakeholders undertake an intensified effort to design a school-centric survey and implement effective and efficient interventions to decrease undernutrition among primary school-aged children.

\section{Methods}

\section{Source of evidence}

Systematic review and meta-analysis from computerized databases and gray literatures form the evidentiary bases of this study.

\section{Searching strategies and data selection}

Preferred reporting items for systematic review and metaanalysis (PRISMA) guidelines were used to prepare and present this systematic reviews and meta-analysis [18]. To identify relevant articles, a comprehensive search between 2006 and September 3, 2019 was performed in the databases of PubMed, Science Direct, Google Scholar, and Cochrane Library. All searches were limited to articles written in English and grey literature was searched through the review of reference lists and hand searches. Moreover, to find unpublished papers, select research centers, including Addis Ababa Digital Library and Saint Mary's University repositories were searched. Studies identified by our search strategy were retrieved and managed using Endnote X7 (Thomson Reuters, Philadelphia, PA, USA) software. The search was conducted from September 1 to November 25, 2019. During the search process the authors used the following keywords and $\mathrm{MeSH}$ terms: prevalence AND undernutrition OR stunting OR wasting OR underweight OR thinness AND associated factor OR determinant factor AND primary schoolaged children AND Ethiopia.

\section{Study population \\ Inclusion criteria}

Study area All studies conducted in Ethiopia.

Study design All observational study designs reporting the prevalence of undernutrition. 
Population Studies involving primary school-aged children $(6-15$ years).

Language Only articles reported in English language.

Publication condition Published and unpublished articles.

Exclusion criteria Articles, which were not fully accessible after two-email contacts, were excluded because of inability to assess the quality of articles in the absence of full text.

\section{Data extraction}

All relevant articles were screened and extracted by two authors (AA and MM) independently using a standardized data extraction format in Microsoft ${ }^{\text {tm }}$ Excel tool adapted from the Joanna Briggs Institute (JBI) [19]. Name of first authors, publication year, study area, study province, study design, mean age, response rate, sample size, and $95 \%$ CI prevalence of undernutrition as (stunting, underweight and thinness/wasting) were extracted from all selected full papers.

\section{Quality assessment}

In this meta-analysis, the qualities of the included article were assessed using a modified version of the Newcastle-Ottawa Scale for cross-sectional studies adopted from Madhavan et al. [20]. This tool has three main sections. The first section, scored on the basis of one to five stars, focuses on methodological quality of each study (i.e., sample size, response rate, and sampling technique). The second section of the tool considers the comparability of the study cases with a possibility of two stars to be gained. The last section is concerned with the outcomes and statistical analysis of the original study with a possibility of three stars to be gained. In addition, quality appraisal of included studies was evaluated by two authors (MD and MM) independently and any discrepancy was resolved by a third author (MA). Articles attaining a Newcastle-Ottawa Scale (NOS) score of $\geq 7$ stars out of 10 were considered as high quality and eligible for inclusion. In this study, all eligible studies were determined to have high quality scores.

\section{Risk of bias assessment}

Two authors (DB and MA) assessed the risk of bias for included articles independently by using the Hoy et al.'s internal and external validity tool for prevalence studies based on a review of the literature [21]. The tool consists of ten items addressing four domains of bias plus a summary risk of bias assessment [21]. Any scoring difference was resolved by discussion mediated by a third author (AM).

\section{Data collection tool used by included studies}

All included studies used a structured pre-tested questionnaire for face to face interviews and anthropometric measurement for weight was measured with minimal clothing and no shoes using an electronic beam balance in kilogram $(\mathrm{kg})$ to the nearest of $0.1 \mathrm{~kg}$ and length was measured with standing position in centimeters $(\mathrm{cm})$ to the nearest of $1 \mathrm{~cm}$. Finally the anthropometric measures of weight, height, and age values were converted into Zscores of the indices according to WHO standards [22]. Since the tools used by primary studies are pre-tested and standard measurements were used at various settings, it permits meaningful comparisons.

\section{Outcome assessment}

There were two outcomes considered for this systematic review and meta-analysis. The first outcome was to determine the pooled prevalence of undernutrition in terms of stunting, underweight and thinning/wasting among primary school-aged children in Ethiopia. Underweight is reflected when the weight for age is more than 2 standard deviations (SD) below the WHO Child Growth Standards median; stunting reported when height for age is more than $2 \mathrm{SD}$ below of the WHO Child Growth Standards median; and wasting is weight for height is more than 2 SD below the WHO Child Growth Standards median [23].

The second outcome was to identify determinant factors of undernutrition in the form of the log odds ratio. For each factor, the odds ratio was calculated based on the binary outcome data reported by each study. If the factors were not reported in sufficient details across studies (less than two studies), the log odds ratios were not pooled. A narrative synthesis for the reports of systematic reviews was done for quantitative data as forest plots without pooled estimates, which were not appropriate for metaanalysis due to low number. The factors assessed for this review was educational status of mothers (illiterate versus literate), sex of the child (female versus male), age of children (5-10 years versus $10-15)$, family size $(<5$ versus $>$ $5)$, frequency of meals per day $(\leq 3$ versus $>3)$, infection (yes versus no), source of water (protected versus unprotected), hand washing with soap (yes versus no), and availability of latrine (yes versus no).

\section{Data processing and analysis}

A Microsof ${ }^{\text {min }}$ Excel spreadsheet form was used to present the extracted data from the primary study and further analysis was done by STATA/se ${ }^{\mathrm{Tm}}$ Version 14 statistical software. The standard error was calculated based on binomial distribution. Heterogeneity was assessed by computing $p$-values of Higgins's $I^{2}$ test statics and Q-statistics among reported prevalence. Higgins's $I^{2}$ statistic measures the difference between sample estimates (in percentage) 
which is due to heterogeneity rather than to sampling error. The pooled effect was estimated with a random effects meta-analysis model. Subgroup analysis was performed based on study province, sample size, and publication year to minimize random variations between the estimates of the primary study. In addition, univariate meta-regression was computed to identify the possible sources of heterogeneity by considering sample size, quality score, and publication year. Publication bias was assessed visually by funnel plot and statistically supported with confirmatory and/or objectivity testing with Egger's and Begg's test at a 5\% level of significance [24]. Point prevalence, as well as $95 \%$ confidence intervals, was presented in a forest plot format. In this plot, the size of each box indicated the weight of the study, while each crossed line referred to a $95 \%$ confidence interval with the mean effect at the center. The determinant factors of undernutrition were determined by a log odds ratio at $95 \%$ level of significance.

\section{Results}

First, 564 studies reported the prevalence of undernutrition and associated factors from the computerized database search. We then excluded 291 articles due to duplication and the remaining 273 studies were assessed for eligibility. A further 146 articles were removed after reading title and abstract. Finally, 30 of 127 articles were found eligible, accessible, and were included for final meta-analysis after reading the full text studies (Fig. 1).

\section{Description of included primary studies}

As described in Table 1, thirty cross-sectional articles published between 2006 and 2019 were including with a total sample size of 16,642 and a response rate of $97.4 \%$.

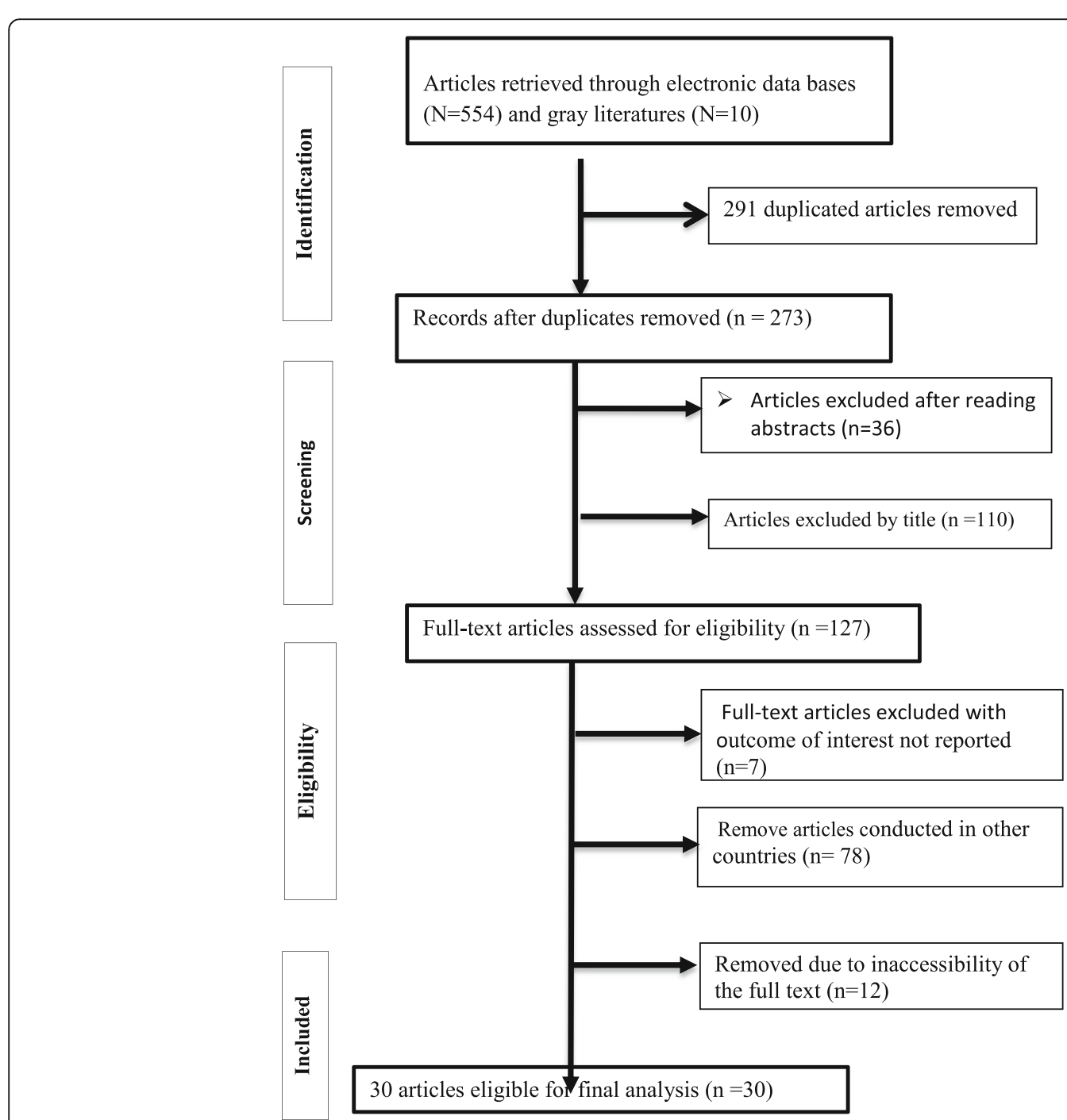

Fig. 1 Flow chart of selecting articles for systematic review and meta-analysis to determine undernutrition among primary school-aged children in Ethiopia 
Table 1 Descriptive summary of 30 articles eligible in the meta-analysis of undernutrition among primary school children in Ethiopia between 2006 and September 2019

\begin{tabular}{|c|c|c|c|c|c|c|c|c|}
\hline \multirow[t]{2}{*}{ Authors } & \multirow{2}{*}{$\begin{array}{l}\text { Publication/ } \\
\text { year }\end{array}$} & \multirow[t]{2}{*}{ Region } & \multirow[t]{2}{*}{ Study area } & \multirow[t]{2}{*}{ Sample } & \multirow[t]{2}{*}{ Response } & \multicolumn{3}{|c|}{ Undernutrition (\%) } \\
\hline & & & & & & Stunting & underweight & wasting \\
\hline Zerfu et al. [25] & 2006 & Addis Ababa & Addis Ababa & 1208 & 100 & 24 & NA & NA \\
\hline Worku et al. [26] & 2009 & Amhara & Gondar & 322 & 100 & 27 & 34.8 & 50 \\
\hline Reji et al. [27] & 2011 & Oromia & Adama & 358 & 99.7 & 12.6 & 7.2 & NA \\
\hline Nguyen et al. [28] & 2012 & Amhara & Angolela & 664 & 95.5 & 11 & 20.8 & 19.6 \\
\hline Amare et al. [29] & 2012 & Amhara & Gondar & 100 & 97 & 23 & 11 & 18 \\
\hline Amare et al. [30] & 2013 & Amhara & Gondar & 405 & 100 & 25 & 15 & 8.9 \\
\hline Mahmud et al. [31] & 2013 & Tigray & Mekelle & 600 & 97.2 & 35 & NA & 34 \\
\hline Kidane et al. [32] & 2014 & Tigray & Wukero & 384 & 100 & 9.4 & 15.4 & 9.9 \\
\hline Mekonnen et al. [33] & 2014 & Oromia & Fincha & 458 & 98.9 & 11.5 & NA & 13.2 \\
\hline Damie et al. [34] & 2015 & Oromia & Chiro & 319 & 91.2 & 7.2 & 24.4 & NA \\
\hline Wolde M et al. [35] & 2015 & SNNP & Dale & 450 & 98.8 & 10.3 & 19 & 14 \\
\hline Alelign et al. [36] & 2015 & Amhara & Durbet & 403 & 95.3 & 11.2 & 27.1 & NA \\
\hline Degarege et al. [37] & 2015 & Addis Ababa & Addis Ababa & 459 & 100 & 19.6 & 15.9 & NA \\
\hline Begna et al. [38] & 2016 & SNNP & Delo-mena & 518 & 95 & 4.5 & 13.6 & 17.1 \\
\hline Zerdo et al. [39] & 2017 & SNNP & Chencha & 406 & 100 & 8.9 & 4.2 & NA \\
\hline Tefera et al. [40] & 2017 & Harerie & Babile & 632 & 100 & 12.8 & NA & 18.1 \\
\hline Birmeka et al. [41] & 2017 & SNNP & Enemorena & 641 & 100 & 39 & 11.8 & 40.9 \\
\hline Wordofa et al. [42] & 2017 & Oromia & Sululeta & 510 & 100 & 10.8 & NA & NA \\
\hline Molla et al. [43] & 2018 & SNNP & Yirgacheffe & 448 & 98.9 & 10.8 & 12.9 & 5.2 \\
\hline Menber et al. [44] & 2018 & Amhara & Haik & 388 & 93.7 & 11.3 & NA & NA \\
\hline Asmare et al. [45] & 2018 & Amhara & Markos & 436 & 98.6 & 27.5 & 20.4 & 8.5 \\
\hline Hailegebriel et al. [46] & 2018 & Amhara & Bair Dar & 422 & 90.5 & 41.6 & 25.9 & 26.7 \\
\hline Tariku et al. [47] & 2018 & Amhara & Arba Minch & 389 & 96 & 41.9 & NA & 8 \\
\hline Enyew et al. [48] & 2018 & Amhara & DebreTabou & 399 & 100 & 32.4 & 24.3 & NA \\
\hline Lisanu et al. [49] & 2018 & Amhara & Mecha & 802 & 99.8 & 37.9 & NA & NA \\
\hline Wolde et al. [50] & 2019 & SNNP & Meskan & 408 & 93 & 16.9 & NA & NA \\
\hline Belay et al. [51] & 2019 & Amhara & Armachiho & 848 & 97.6 & 35.5 & NA & 9.9 \\
\hline Getaneh et al. [52] & 2019 & Amhara & Gondar & 523 & 96.5 & 46.5 & NA & 8.8 \\
\hline Bantie et al. [53] & 2019 & Amhara & $\mathrm{BDR}$ & 370 & 98.6 & 15.1 & NA & NA \\
\hline Felek et al. [54] & 2016 & Amhara & Mecha & 2372 & 94.5 & NA & 24.4 & 10.8 \\
\hline
\end{tabular}

The smallest sample size was 97 in a study in Gondar, Amhara [32] while the largest sample size was 2241 in a study done at Bahir Dar and Mecha, Amhara [54].

Regarding the prevalence of undernutrition, the smallest prevalence of stunting was $4.5 \%$ [38] while the largest was $46.5 \%$ [52]. The prevalence of underweight ranged from $4.2 \%$ [39] to $34.8 \%$ [26]; whereas wasting (thinness) ranged between $5.2 \%$ [43] to 50\% [26].

\section{Meta-analysis of undernutrition among primary school children in Ethiopia}

Thirty articles with a pooled sample size of 16,642 school-aged children and response rate of $97.4 \%$ were considered in this systematic review and meta-analysis. The pool prevalence of stunting, underweight, and wasting in Ethiopia were 21.3\% (95\% CI: 17.0, 25.5), 18.2\% (95\% CI: $14.4,22.0)$, and $17.7 \%$ (95\% CI: 13.5, 21.8) respectively (Figs. 2, 7 \& 8).

\section{Stunting}

The estimated prevalence of stunting among schoolaged children in Ethiopia from 29 articles was 21.3\%. There was high heterogeneity found within the included articles as revealed in forest plot (I $2=98 \%$, $p<0.001$ ) (Fig. 2). 


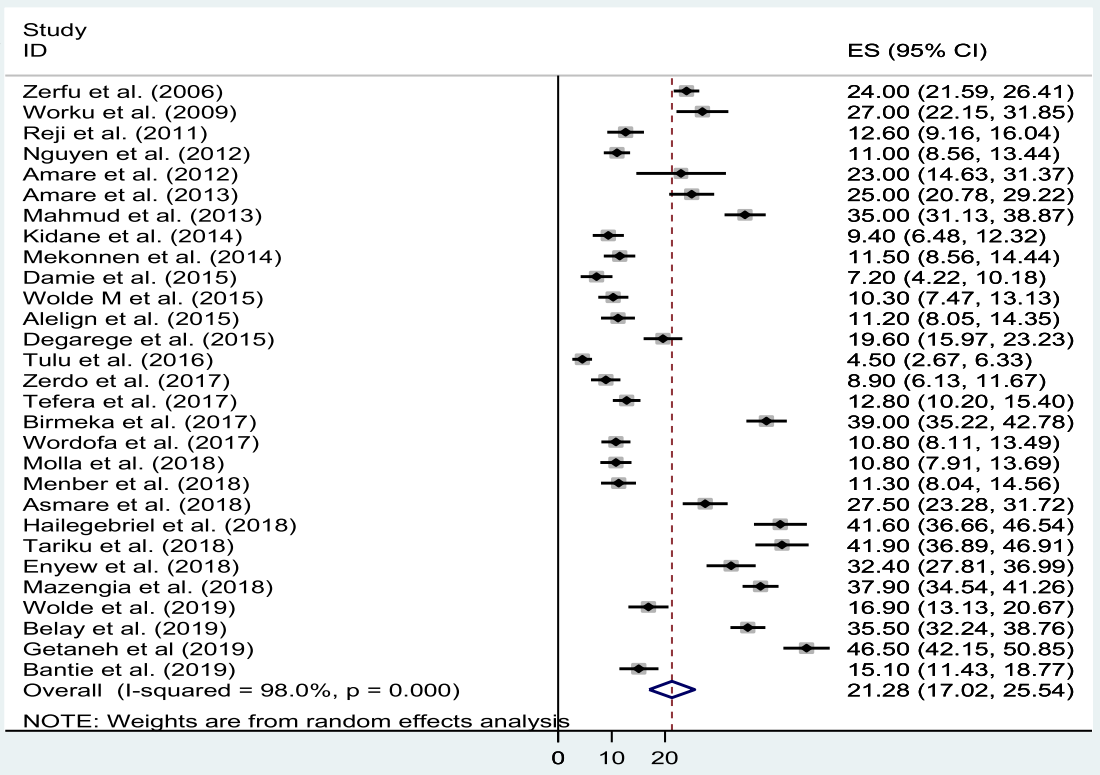

Fig. 2 Forest plot of the pooled prevalence of stunting among school-aged children in Ethiopia

Thus, the subgroup analysis in the study province provide the highest prevalence of stunting in Amhara region 27.6\% (95\% CI: 20.7, 34.5) $\left(\mathrm{I}^{2}=97.8, p<0.001\right)$ followed by Southern Nations, Nationalities and People's (SNNP) Region 15.0\% (95\% CI: 26.5, 23.4) $\left(\mathrm{I}^{2}=98.2, p<0.001\right.$ ) and the lowest was noted in Oromia Region $10.5 \%$ (95\% CI: $8.2,12.7)\left(\mathrm{I}^{2}=54.8, p=0.084\right)$ (Table 2$)$.

Table 2 Subgroup analysis of primary school children undernutrition (stunting, underweight and wasting) by study province/region of Ethiopia between 2006 and September 2019

\begin{tabular}{lllll}
\hline $\begin{array}{l}\text { Category of } \\
\text { undernutrition }\end{array}$ & $\begin{array}{l}\text { Province/ } \\
\text { region }\end{array}$ & $\begin{array}{l}\text { Study } \\
\text { number }\end{array}$ & $\begin{array}{l}\text { Sample } \\
\text { size }\end{array}$ & $\begin{array}{l}\text { Prevalence of } \\
\text { undernutrition }\end{array}$ \\
\hline Stunting & Amhara & 14 & 6471 & $27.6(20.7,34.5)$ \\
& SNNP & 6 & 2871 & $15(6.5,23.4)$ \\
& Oromia & 4 & 1645 & $10.5(8.2,12.7)$ \\
& Tigray & 2 & 984 & $2202(2.9,47.3)$ \\
& Addis Ababa & 2 & 1667 & $22.0(17.7,26.3)$ \\
& Hararie & 1 & 632 & $12.8(10.2,15.4)$ \\
& Amhara & 10 & 5523 & $22.7(19.2,26.3)$ \\
& SNNP & 5 & 2463 & $12.2(7.1,17.2)$ \\
& Oromia & 2 & 677 & $15.7(1.2,32.4)$ \\
& Tigray & 1 & 384 & $15.4(11.8,19.0)$ \\
& Addis Ababa & 1 & 459 & $15.9(12.6,19.3)$ \\
& Amhara & 10 & 6481 & $16.5(11.7,21.3)$ \\
& SNNP & 4 & 2057 & $19.3(5.1,33.4)$ \\
& Oromia & 1 & 458 & $13.2(10.1,16.3)$ \\
& Hararie & 1 & 632 & $18.1(15.121 .1)$ \\
\hline
\end{tabular}

The presence of publication bias was assessed with subjectivity test of bias funnel plot visually and found substantially asymmetric and a further confirmatory test of objectivity to indicate publication bias was done with Egger's test ( $p$-value < 0.001) (Fig. 3). Even though the funnel plot showed substantial symmetry, the Egger's test shows presence of bias. Thus, we performed a nonparametric trim and fill analysis to handle the observed publication bias for estimating the number of missing studies that might exist and in reducing and adjusting publication bias in metaanalysis.

\section{Factors associated with stunting in Ethiopia}

In this systematic review and meta-analysis of stunting in Ethiopia, the associated factors affecting stunting were frequency of meals three times per day with odd ratio of $0.45(95 \% \mathrm{CI}: 0.28,0.72)$ and hand washing practice with odds of $0.73(95 \%$ CI: $0.48,1.12)$ were reported from a single article as a result were not able to generate the pooled estimate. Family size of below five members was reported from three studies with pooled odd ratio of 7.95(95\% CI: 0.62, 15.3), which was not found statistically significant.

Sex with pooled odd ratio of 0.73 (95\% CI: 0.62, 0.85), age of children with pooled odd ratio of 0.56 (95\% CI: $0.44,0.72$ ), and maternal education with pooled odd ratio of $1.91(95 \%$ CI: $1.33,2.73)$ were found statistically significant. As we have examined the association between sex and stunting among school-aged children from seven [7] studies; the findings showed that sex had 


\section{Funnel plot with pseudo $95 \%$ confidence limits}

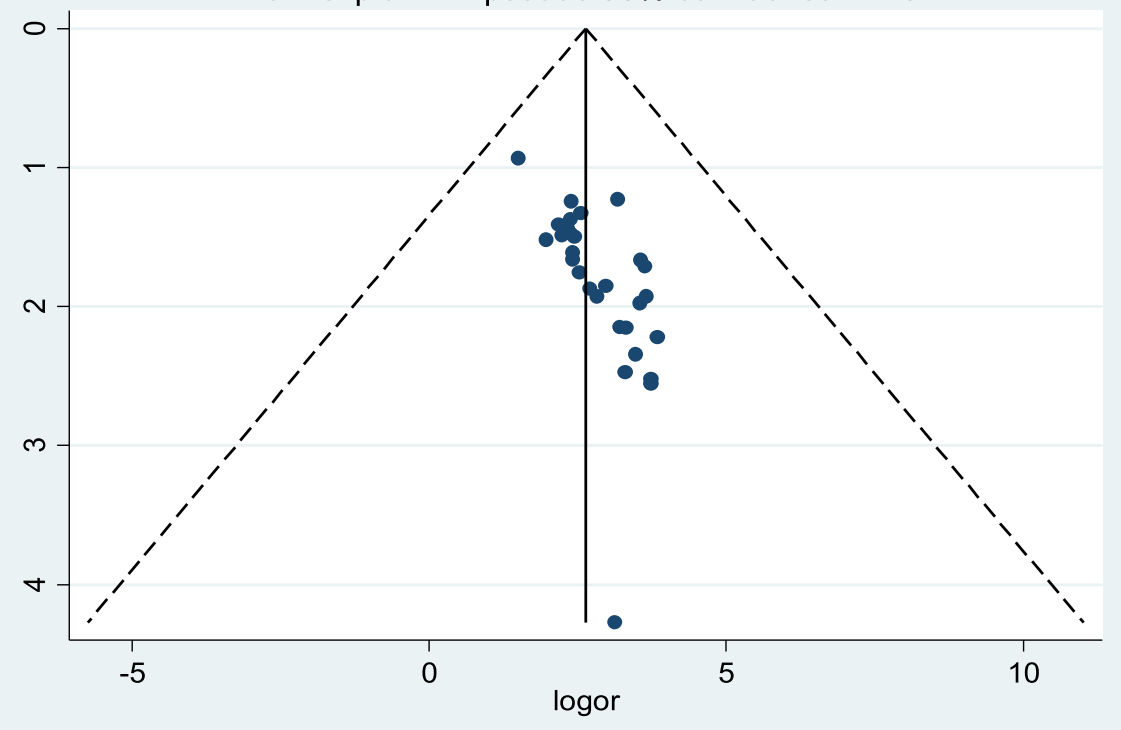

Fig. 3 Funnel plot with 95\% confidence limits of the pooled prevalence of stunting among school-aged children in Ethiopia

an association with prevalence of stunting, with the odds of stunting $27 \%$ higher among males as compared to females $(\mathrm{OR}=0.73,95 \% \mathrm{CI}: 0.62,0.85)$. The results did not indicate presence of heterogeneity ( $\mathrm{I} 2=0.0 \%$ and $p=0.734$ ) (Fig. 4).

The association between age category and stunting was calculated from eight studies. Accordingly, the odds of stunting was $79 \%$ higher among school-aged children less than 10 years of age as compared to children $10-15$ years old ( $\mathrm{OR}=0.56,95 \% \mathrm{CI}$ : 0.44 , 0.72 ). The statistics showed moderate heterogeneity (I $2=55.3 \%$ and $p=0.028)$ across the included studies (Fig. 5).

We observed the association between maternal education and stunting from eight studies. The prevalence of stunting was 1.91 times higher among school-aged

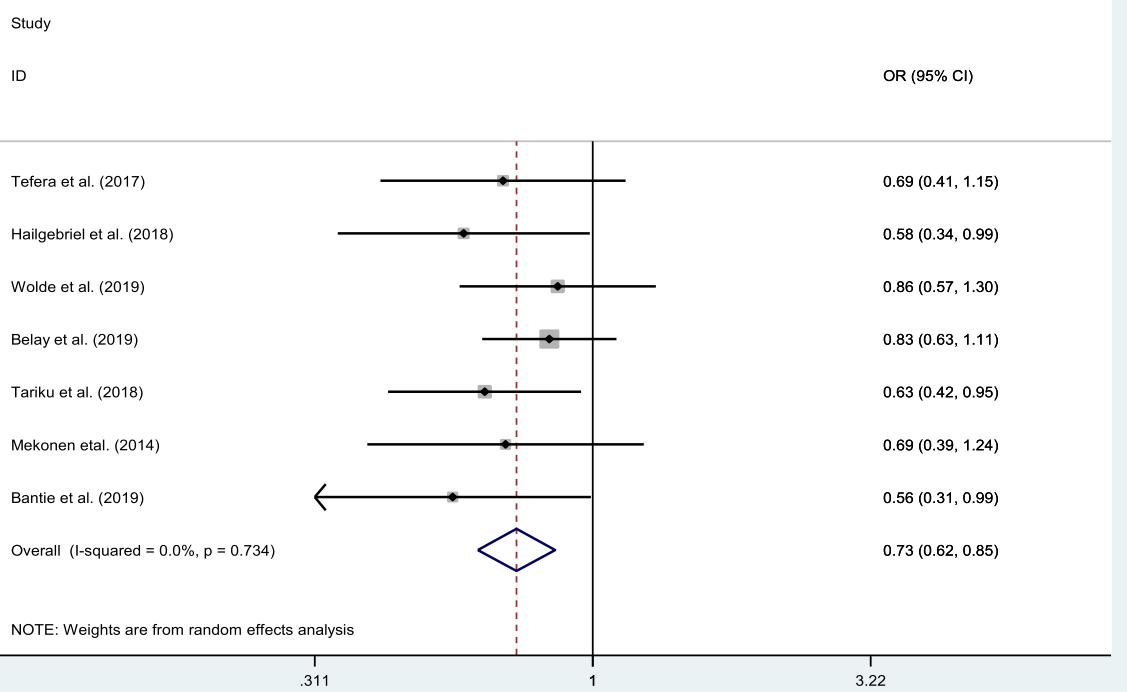

Fig. 4 Pooled odd ratio between stunting and sex of school-aged children 


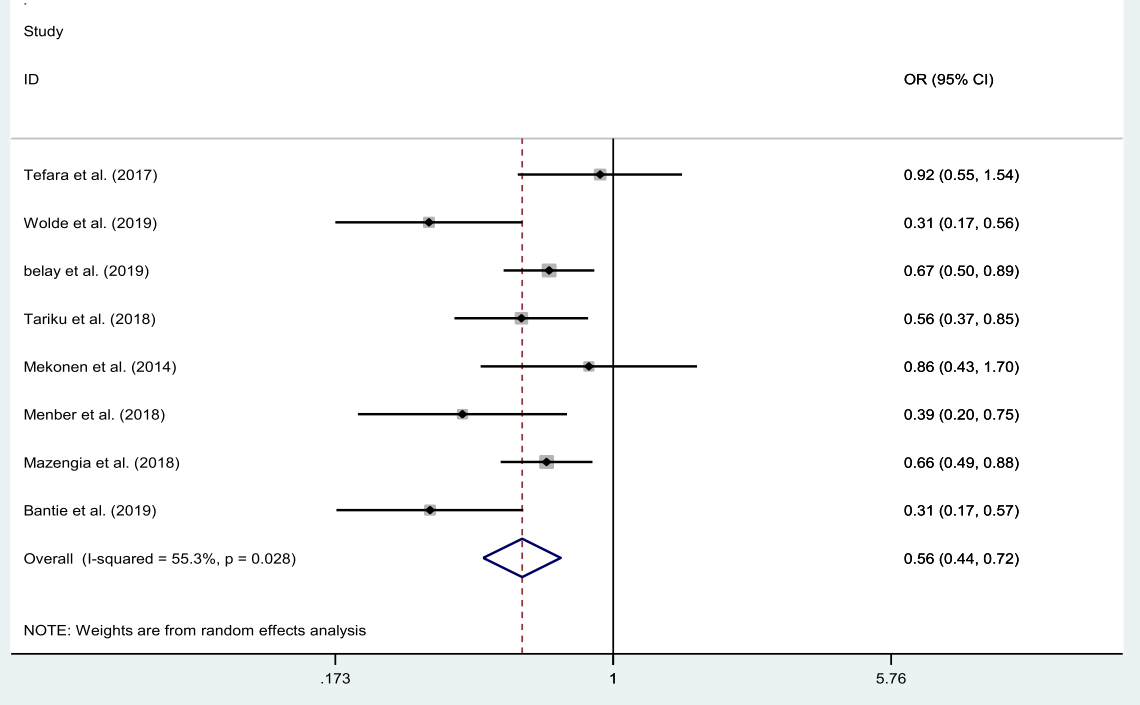

Fig. 5 Pooled odd ratio between stunting and school-aged children

children whose mothers had no formal education in comparison to the more educated cohort $(\mathrm{OR}=1.91$, $95 \%$ CI: 1.33, 2.73). The resulting statistics showed moderate heterogeneity ( $\mathrm{I} 2=70 \%$ and $p=0.002)$ across the included studies (Fig. 6).

\section{Underweight}

Prevalence of underweight in school-aged children in Ethiopia from 18 studies was $18.2 \%$. A high heterogeneity was observed across the included articles as revealed in forest plot (I2 $=96.1 \%, p<0.001)$ (Fig. 7).

Subsequently, subgroup analysis by the study province to indicate source of heterogeneity provides the highest prevalence of underweight at 22.7\% (95\% CI: 19.2 , 26.3 $)\left(\mathrm{I}^{2}=88.1, p<0.001\right)$ in Amhara region followed by $12.2 \%$ (95\% CI: 7.1, 17.2) $\left(\mathrm{I}^{2}=94.1, p<\right.$ 0.001) in SNNP region (Table 2).

Study

OR $(95 \% \mathrm{Cl})$

Tefera et al. (2018)

Hailgebriel et al. (2018)

Wolde et al. (2019)

Tariku et al. (2018)

Mekonen et al. (2014)

Menber et al. (2018)

Mazengia et al. (2018)

Bantie et al. (2019)

Overall $(1$-squared $=70.0 \%, p=0.002)$

NOTE: Weights are from random effects analysis

.145

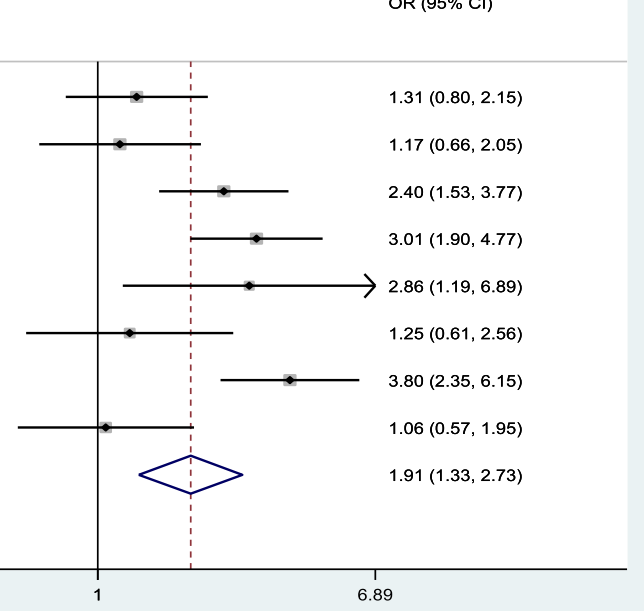

Fig. 6 Pooled odd ratio between stunting and maternal educational status 


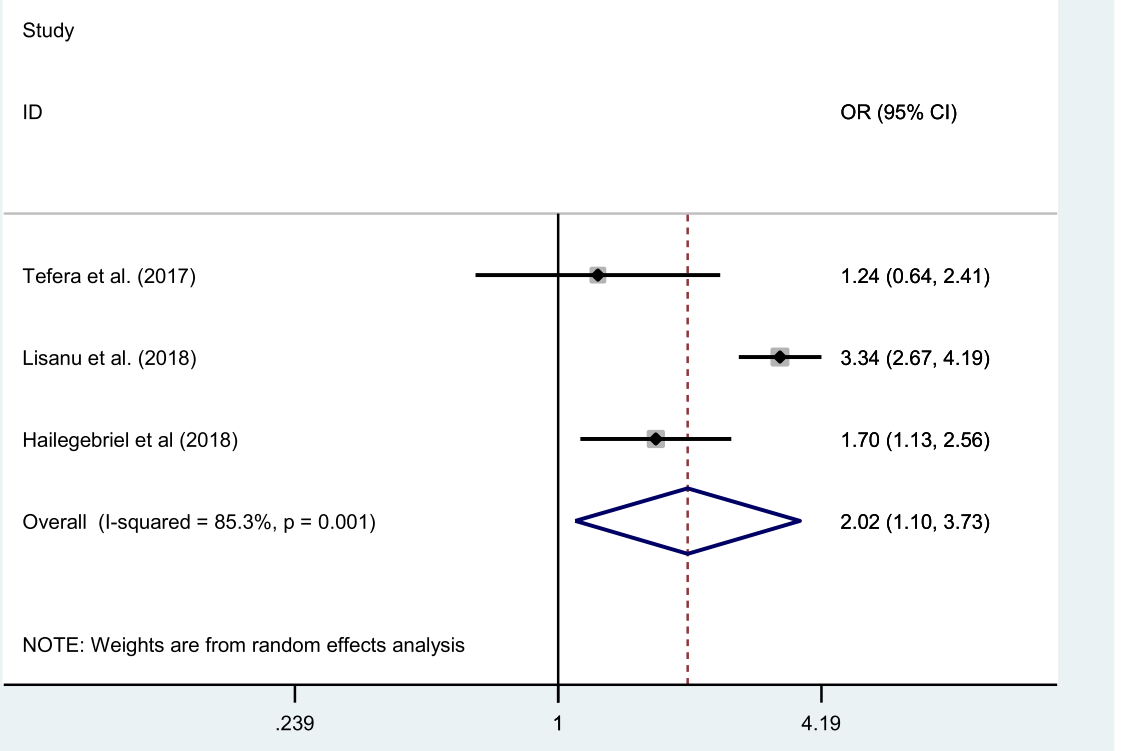

Fig. 7 Forest plot of the pooled prevalence of underweight among school-aged children in Ethiopia

\section{Factors associated with underweight in Ethiopia}

As we have studied the associated factors of underweight among school-aged children in Ethiopia, we had observed protected source of water and hand washing with soap were reported form only one article as associated factor with underweight with odd ratio of 1.18 (95\% CI: $0.7,1.98)$ and $2.62(95 \%$ CI: $1.02,6.72)$ respectively. Two factors (sex of school-aged children and educational status of mothers) were reported consistently over three different articles but both were not statistically associated with underweight $(\mathrm{OR}=1.17,95 \% \mathrm{CI}$ : 0.54, 2.56) and $(\mathrm{OR}=1.00,95 \% \mathrm{CI}: 0.44,2.30)$ respectively.

The presence of parasitic infection reported from three studies with pooled odd ratio $2.02(95 \% \mathrm{CI}: 1.10,3.73)$ was found significantly significant. Thus, the prevalence of underweight was two times higher among those children infected with parasitic infection as compared to non-infected children (Fig. 8).

\section{Wasting}

The pooled estimates of wasting in Ethiopia among school-aged children from 18 articles was $17.7 \%$ and the heterogeneity between the studies were observed across the included articles as revealed in forest plot (I2 = 97.5\%, $p<0.001$ ) (Fig. 9).

Accordingly, the subgroup analysis by study province to show source of heterogeneity of wasting among the included articles indicated the highest prevalence of wasting was observed at $19.3 \%$ (95\% CI: 5.1, 33.4) $\left(\mathrm{I}^{2}=\right.$ 98.9, $p<0.001)$ in SNNP followed by $16.5 \%$ (95\% CI:
11.7, 21.3) $\left(\mathrm{I}^{2}=96.9, p<0.001\right)$ in Amhara region (Table 2 ). To determine publication bias, we performed funnel plot to show bias graphically, yielding moderate asymmetry. Further confirmation of bias was assessed with objectivity Egger's test, the presence of publication bias was noted with ( $p$-value $=0.005)$ (Fig. 10). A nonparametric trim and fill analysis was conducted to handle and adjusting the observed publication bias.

\section{Factors associated with wasting in Ethiopia}

The association between age category and wasting was calculated from six studies. The prevalence of wasting was 2.74 times higher among school-aged children 5 to10 years age as compared to those aged 10 to15 years $(\mathrm{OR}=2.74,95 \% \mathrm{CI}: 1.81,4.14)$ from a random effects model. The result of the statistics showed moderate heterogeneity ( $\mathrm{I} 2=76.1 \%$ and $p=0.001)$ across the studies (Fig. 11).

In addition we have calculated the log odds ratio for educational status of mothers on wasting/thinness of school-aged children, finding that the odds of wasting is 1.66 times higher among children at the age of 5 to 10 years as compared to 10 to15 years of age $(\mathrm{OR}=0.6$, 95\% CI: 0.36, 0.9). Moderate heterogeneity was observed over the included studies with their respective log odds ratio ( $\mathrm{I} 2=76.1 \%, p=0.001)$ (Fig. 12 ).

\section{Discussion}

Primary school children are amongst the most vulnerable segments of the population for undernutrition, 


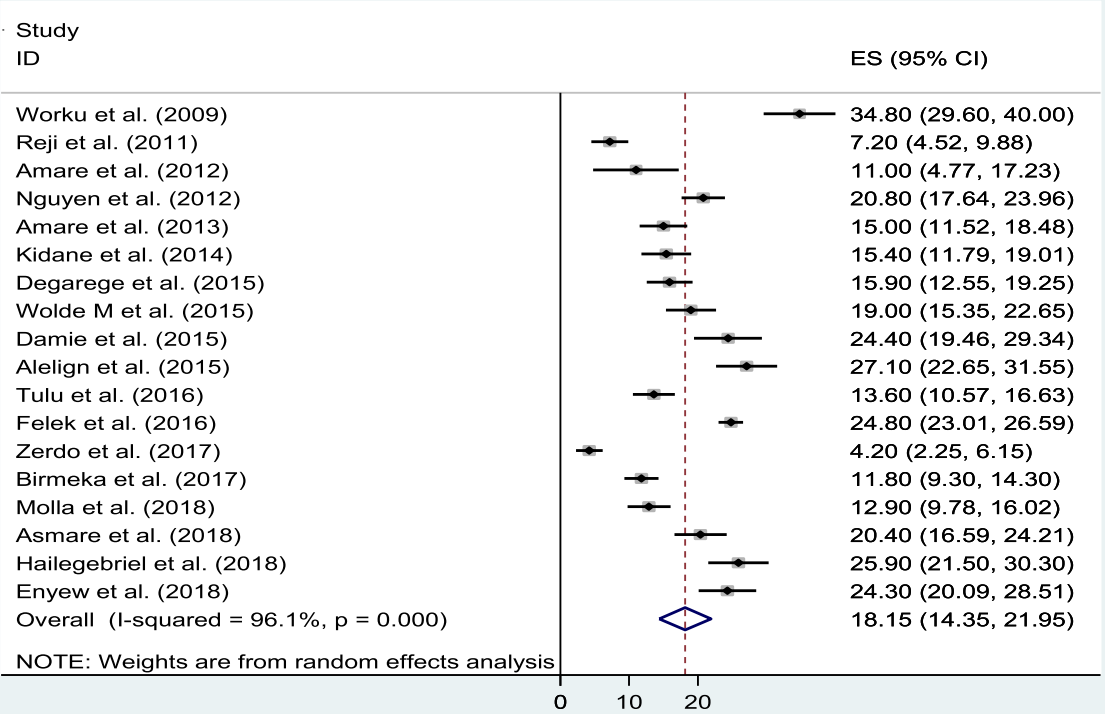

Fig. 8 Pooled odd ratio between underweight and parasitic infection

which is one of the key indicators for improving health, academic performance, and country development. Undernutrition among school-aged children is explained with the three common anthropometric indicators includes height-for-age (stunting), weight-for-age (underweight) and weight-for-height (thinness/wasting) [25]. Hence, the effect of undernutrition on child morbidity and mortality reduction can be determined by considering all undernutrition indicators through appropriate and standard anthropometric measurements [27] making this systematic review and meta-analysis important to show what is currently known about undernutrition among primary school children at the national level.

In our study, the prevalence of stunting, underweight, and wasting/thinness in Ethiopia were found to be 21.3, 18.2 and $17.7 \%$ respectively among primary school children. The magnitude of stunting in this study is relatively congruent with the studies conducted in west

Study
ID
Worku et al. (2009)
Amare et al. (2012)
Nguyen et al. (2012)
Amare et al. (2013)
Mahmud et al. (2013)
Kidane et al. (2014)
Mekonnen et al. (2014)
Wolde M et al. (2015)
Felek et al. (2016)
Tulu et al. (2016)
Tefera et al. (2017)
Birmeka et al. (2017)
Molla et al. (2018)

Fig. 9 Forest plot of the pooled prevalence of wasting/thinness among school-aged children in Ethiopia 


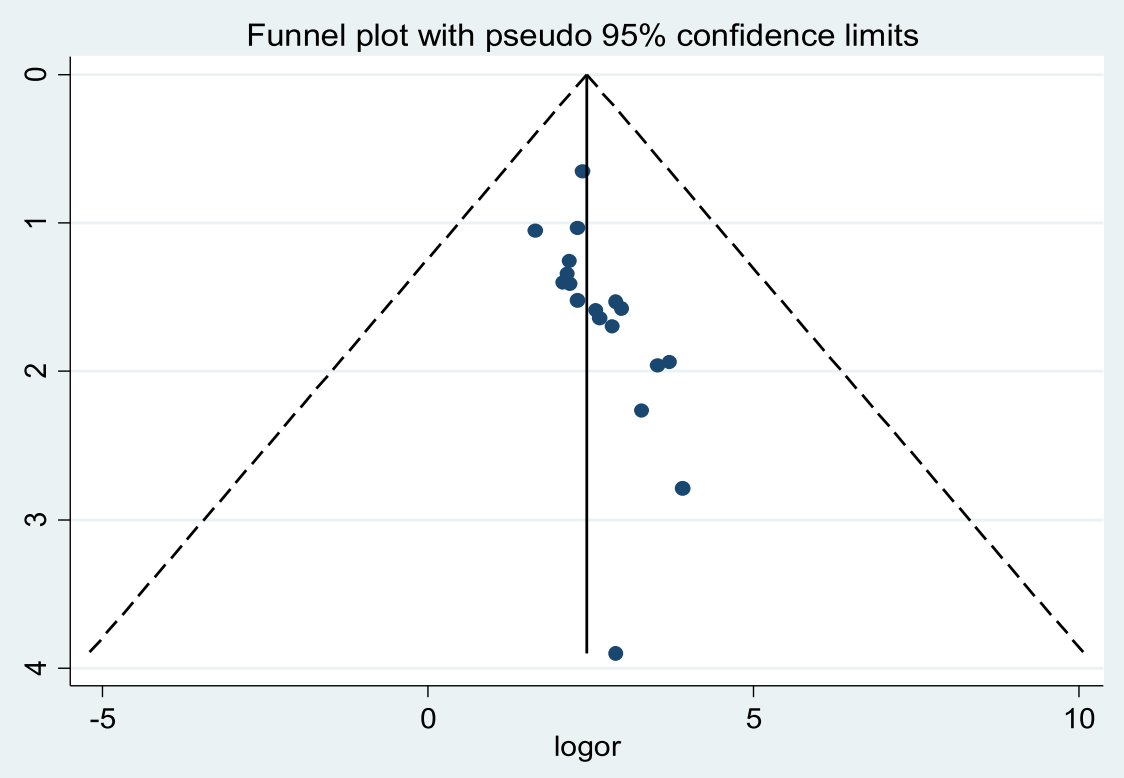

Fig. 10 Funnel plot with 95\% confidence limits of the pooled prevalence of thinness among school-aged children in Ethiopia

Bengal 23.0\% [28] and Mexico 22.3\% [29]; lower than findings from China (25.6\%) [30], Indonesia (28.11\%) [31] and Egypt (34.2\%) [33], and higher than reports from Iraq (18.7\%) [34], India (17\%) [35] and Nigeria (17.4\%) [36]. Underweight school-aged children in Ethiopia (18.2\%) in this study showed lower levels from than reports from Bangladesh (43\%) [37], Yemen (46.2\%) [40], and Nepal (27.4\%) [41] but higher than a report from Tanzania (5.7\%) [42]. The third anthropometric indicators of undernutrition is wasting (thinness) which, in our study, had higher prevalence than the studies done in the western region of Nepal (12\%) [44] and Burkina Faso (13.7\%) [45]. In contrast, it is lower than a study from Ghana at $19.4 \%$ [46]. The possible explanation for these variations could be attributable to the difference in the parasitic infection, livelihood of the population

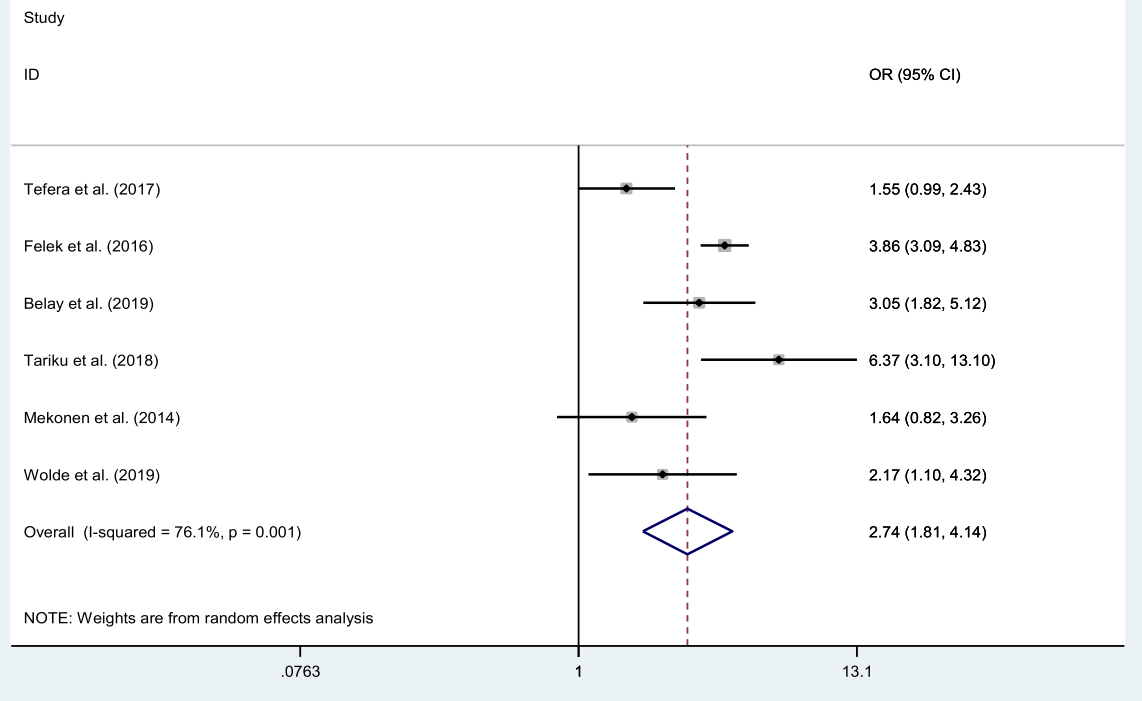

Fig. 11 Pooled odds ratios between thinness and maternal educational status 


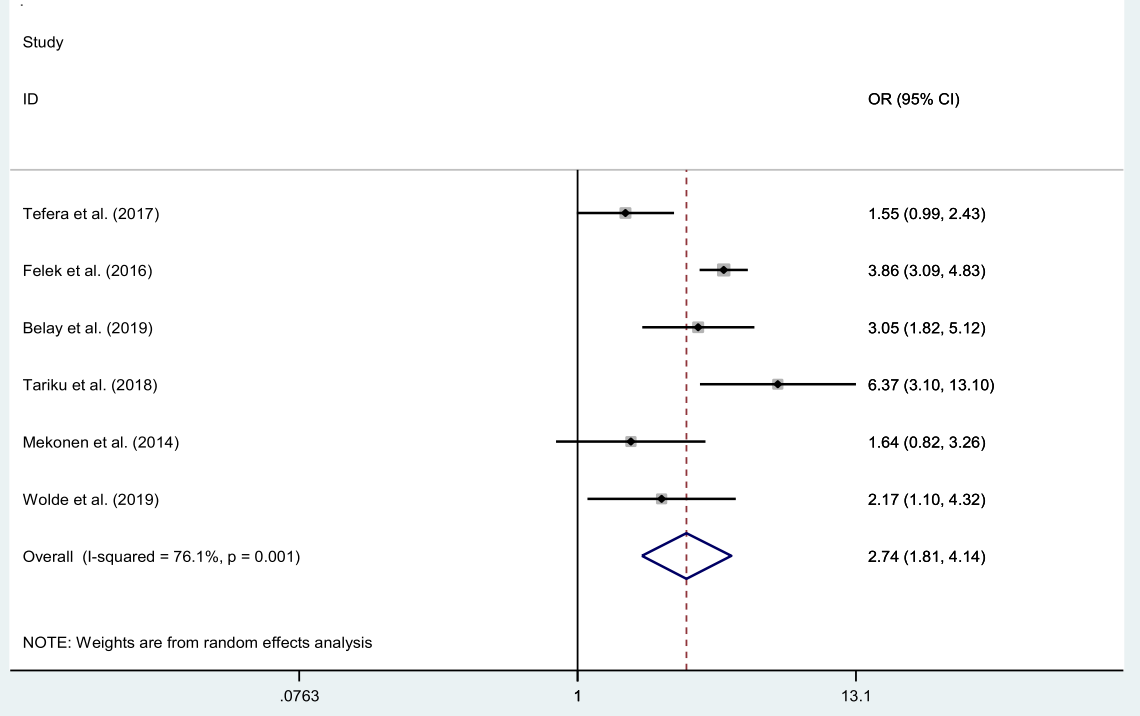

Fig. 12 pooled odd ratio between thinness and school-aged children

economy, seasonal, cultural, socio-economical, and geographical diversity.

Parasitic infection is one of the determinate factors for undernutrition as supporting by the studies conducted in different parts of the world [47, 48]. This could be due to parasitic infection competing for the nutritional intake of children resulting in impairment of the immune systems and contributing to susceptibility to many diseases that extend its impact to underweight and cognitive impairment, decreased school attendance $[49,50]$.

Like the studies conducted in Bangladesh and India $[37,51]$, the current study found that the odds of undernutrition were higher in children below 10 years as compared to older ones which reflects the nature of stunting as a chronic nutritional problem. This could be due increased risk of intestinal parasitic infection among younger age hand less habit of not washing hands before eating among and cannot protect themselves from parasitic infection sources.

Being male was found to be a higher risk factor for malnutrition similar to previous work conducted in India [51]. This could be male children are usually more mobile and undertake different playing activities that make them loss grater energy from their body. On the other hand, females are usually give more attention to their personal hygiene than males and less mobile in their behavior and stay at home, have more access to different food staff at early age [53].

In addition, maternal educational status is a significant contributing factor for undernutrition. Similar to the studies in Indonesia and Nigeria [31,36], the odds of undernutrition for primary school children were higher among mothers who had not formal education (illiterate) as compared to the literate cohort. This finding could be explained by educated mothers having better understanding of how to maintain the health of their child and their nutrition with the available resources. They can also contribute greater effort at home and can raise productivity and contributions of the women to the families' economic situations, bring attention to improved child nutrition, and regulate the family size. As a result, education of girls is education of all and ultimately would be the wise method of reducing undernutrition.

\section{Limitation of the study}

This systematic review and meta-analysis included only English language reports which may have restricted inclusion of some locally relevant articles. Some of the studies included in this review had small sample sizes such as 100 . This meta-analysis represented only studies reported from five of nine regions (Amhara, Oromia, Tigray, Hararie and SNNP) and one of two administrative towns (Addis Ababa) of the country which could compromise the estimates of nutritional status at the national level.

\section{Conclusion}

The prevalence of undernutrition, stunting, and underweight are moderately high while thinness (wasting) is at critical state among primary school children found to be greater than the under-five age group's national average in 2016 EDHS. Therefore, this finding warrants the 
design of a school-based nutrition survey and implementation of programs to improve the nutritional status of primary school children in the country. In addition, special emphasis should be given for school aged children in the early stages of school years, creating programs targeting mothers who lack formal education, as well as preventing and early treating/deworming for parasitic infections. Moreover, the researchers try to conduct research on province/regions not yet studied for their school age children nutritional status to date.

\section{Abbreviations \\ Cl: Confidence Interval; EDHS: Ethiopian Demography and Health Survey; JBI: Joanna Briggs Institute; OR: Odds Ratio; PRISMA: Preferred Reporting Items for Systematic Review and Meta-Analysis; SD: Standard Deviation; SNNP: Southern Nation and Nationality and People; WHO: World Health Organization}

\section{Acknowledgements}

Authors of primary studies.

\section{Authors' contributions}

MA: Conception of research protocol, study design, literature review, data extraction, data analysis, interpretation and drafting the manuscript. AA: Study design and contribute on data extraction, quality assessment, data analysis and manuscript review. DB: Literature review, data extraction, data analysis, interpretation and drafting the manuscript. AM: Contribute on data extraction, quality assessment, data analysis and manuscript review. PP: Manuscript review, quality assessment, and language editing. MD: Contribute on Literature review, data extraction, quality assessment, and manuscript review. MM: Contribute on conception, literature review, data extraction, quality assessment. All authors have read and approved the manuscript.

\section{Funding}

Not applicable.

\section{Availability of data and materials}

Minimal data can be accessed upon request from first author (MAA).

Ethics approval and consent to participate

Not applicable.

\section{Consent for publication}

Not applicable.

\section{Competing interests}

The authors declare that they have no competing interests.

\begin{abstract}
Author details
${ }^{1}$ Biostatstics Unit, Department of Public Health, College of Health Science, Debre Markos University, P.O. Box: 269, Debre Markos, Ethiopia. ${ }^{2}$ Department of Human Nutrition and Food Sciences, College of Health Sciences, Debre Markos University, Debre Markos, Ethiopia. ${ }^{3}$ Biostatstics Unit, College of Health Science, Assossa University, Assossa, Ethiopia. ${ }^{4}$ Department of Midwifery, College of Health Sciences, Debre Markos University, Debre Markos, Ethiopia. ${ }^{5}$ College of Nursing, University of Saskatchewan, Saskatoon, Canada. ${ }^{6}$ School of Life Sciences and Bioengineering, Nelson Mandela African Institute of Science and Technology, Arusha, Tanzania. ${ }^{7}$ Department of Agricultural Economics, College of Agriculture and Resource Management,
\end{abstract} Dilla University, Dilla, Ethiopia.

Received: 2 January 2020 Accepted: 17 August 2020

Published online: 04 September 2020

\section{References}

1. Ethiopia free undernutrition. New National Nutrition Programme II envisions an Ethiopia free 2016. Available from: https://unicefethiopia.org/2016/12/20/ new-national-nutrition-programme-ii-envisions-an-ethiopia-free-ofmalnutrition/.

2. Bundy D, Burbano C, Grosh ME, Gelli A, Juke M, Lesley D. Rethinking school feeding: social safety nets, child development, and the education sector: the World Bank; 2009

3. WHO. WHO Global database on child growth and malnutrition 2008. Available from: https://www.who.int/nutgrowthdb/en/.

4. Black RE, Morris SS, Bryce J. Where and why are 10 million children dying every year? Lancet. 2003;361(9376):2226-34.

5. Hasan I. A study of prevalence of malnutrition in government school children in the field area of Azad nagar Bangalore, India; 2010.

6. Appleby $\amalg$, Tadesse G, Wuletawu Y, Dejene NG, Grimes JE, French MD, et al. Integrated delivery of school health interventions through the school platform: investing for the future. PLoS Negl Trop Dis. 2019;13(1):e0006449.

7. UNICEF W. Levels and trends in child mortality: report 2011. Estimates developed by the UN Inter-agency Group for child mortality estimation New York: United Nation's Children Fund 2011.

8. Britto PR, Ulkuer N. Child development in developing countries: child rights and policy implications. Child Dev. 2012;83(1):92-103.

9. UNICEF. UNICEF The State of the World's Children 2016. Available from: https://www.unicef.org/publications/files/UNICEF_SOWC 2016.pdf.

10. Grantham-McGregor S, Cheung YB, Cueto S, Glewwe P, Richter L, Strupp B, et al. Developmental potential in the first 5 years for children in developing countries. Lancet. 2007;369(9555):60-70.

11. UNITED NATIONS SYSTEM Standing Committee on Nutrition. Report of the Standing Committee on Nutrition at its Thirty-Third Session 2006. 19]. Available from: http://www.unscn.org/files/Annual_Sessions/33rd_SCN_ Session/33rd_session_REPORT.pdf.

12. Engesveen K, Shrimpton R. Nutrition education in the context of the United Nations standing committee on nutrition activities and publications, 19852006. J Nutr Educ Behav. 2007;39(6):351-6.

13. Horton S, Alderman H, Rivera JA. The challenge of hunger and malnutrition. Copenhagen Consensus. 2008:3-4.

14. Drake L, Maier C, Jukes M, Patrikios A, Bundy D. School-age children: their nutrition and health. SCN News. 2002;25:4-30.

15. Intiful FD, Ogyiri L, Asante M, Mensah A, Steele-Dadzie R, Boateng L. Nutritional status of boarding and non-boarding children in selected schools in the Accra metropolis. J Biol Agric Healthc. 2013;3(7):156-62.

16. Frongillo EA Jr. Symposium: causes and etiology of stunting. J Nutr. 1999; 129(2S Suppl):S529-30

17. Sunguya B, Koola J, Atkinson S. Infection associated with severe malnutrition among hspitalised children in East Africa. Tanzan J Health Res. 2006;8(3).

18. Liberati A, Altman DG, Tetzlaff J, Mulrow C, Gøtzsche PC, loannidis JP, et al. The PRISMA statement for reporting systematic reviews and meta-analyses of studies that evaluate health care interventions: explanation and elaboration. PLoS Med. 2009;6(7):e1000100.

19. Munn Z, Moola S, Riitano D, Lisy K. The development of a critical appraisal tool for use in systematic reviews addressing questions of prevalence. Int J Health Policy Manag. 2014;3(3):123-8.

20. Madhavan A, LaGorio L, Crary M, Dahl W, Carnaby G. Prevalence of and risk factors for dysphagia in the community dwelling elderly: a systematic review. J Nutr Health Aging. 2016;20(8):806-15.

21. Hoy D, Brooks P, Woolf A, Blyth F, March L, Bain C, et al. Assessing risk of bias in prevalence studies: modification of an existing tool and evidence of interrater agreement. J Clin Epidemiol. 2012;65(9):934-9.

22. WHO. AnthroPlus for Personal Computers manual Software for assessing growth of the world's children and adolescents 2009. Available from:https:// www.who.int/growthref/tools/ who_anthroplus_manual.pdf.

23. World Health Organization. WHO child growth standards: length/height-forage, weight-for-age, weight-for-length, weight-for-height and body mass index-for-age: methods and development. 2006.

24. Borenstein MHL, Higgins J, Rothstein HR. A basic introduction to fixed-effect and random-effects models for meta-analysis. Res Synth Methods. 2010;1(2): 97-111.

25. Wamani H, Åstrøm AN, Peterson S, Tumwine JK, Tylleskär T. Predictors of poor anthropometric status among children under 2 years of age in rural Uganda. Public Health Nutr. 2006;9(3):320-6

26. Worku N, Erko B, Torben W, Belay M, Kasssu A, Fetene T, et al. Malnutrition and intestinal parasitic infections in school children of Gondar, north West Ethiopia. Ethiop Med J. 2009;47(1):9-16. 
27. Olaf M, Michael K. Malnutrition and health in developing countries. Can Med Assoc J. 2005;2:173

28. Bose K, Bisai S. Prevalence of underweight and stunting among school children in West Bengal. Indian J Pediatr. 2008;75(12):1272.

29. Monarrez-Espino J, Martinez H, Martínez V, Greiner T. Nutritional status of indigenous children at boarding schools in northern Mexico. Eur J Clin Nutr. 2004;58(3):532.

30. Shang Y, Tang L-H, Zhou S-S, Chen Y-D, Yang Y-C, Lin S-X. Stunting and soil-transmitted-helminth infections among school-age pupils in rural areas of southern China. Parasit Vectors. 2010;3(1):97

31. Yasmin G, Kustiyah L, Dwiriani CM. Risk factors of stunting among schoolaged children from eight provinces in Indonesia. Pak J Nutr. 2014;13(10) 557-66.

32. Kidane E, Menkir S, Kebede A, Desta M. Prevalence of intestinal parasitic infections and their associations with anthropometric measurements of school children in selected primary schools, Wukro town, eastern Tigray, Ethiopia. Int J Curr Microbiol App Sci. 2014;3(3):11-29.

33. Abdel Wahed WY, Hassan SK, Eldessouki R. Malnutrition and its associated factors among rural school children in Fayoum governorate, Egypt. J Environ Public Health. 2017;2017.

34. Al Saffar AJ. Stunting among primary-school children: a sample from Baghdad, Iraq; 2009.

35. Bose K, Bisai S, Mukherjee S. Anthropometric characteristics and nutritional status of rural school children. Internet J Biol Anthropol. 2008;2(1).

36. Senbanjo IO, Oshikoya KA, Odusanya OO, Njokanma OF. Prevalence of and risk factors for stunting among school children and adolescents in Abeokuta, southwest Nigeria. J Health Popul Nutr. 2011;29(4):364.

37. Ahsan KZ, El Arifeen S, Al-Mamun MA, Khan SH, Chakraborty N. Effects of individual, household and community characteristics on child nutritional status in the slums of urban Bangladesh. Arch Public Health. 2017;75(1):9.

38. Begna T, Solomon T, Yohannes ZENEBEEA. Intestinal parasitic infections and nutritional status among primary school children in Delo-mena district, south eastern Ethiopia. Iran J Parasitol. 2016;11(4):549.

39. Zerdo Z, Yohanes T, Tariku B, Teshome T. Association between nutritional status and soil-transmitted helminthes re-infection among school-age children in Chencha district, southern Ethiopia: a cross-sectional study. Transl Biomed. 2017;8(2):111.

40. Al-Sobaihi S, Nakamura K, Kizuki M. Undernutrition among children under 5 years of age in Yemen: role of adequate childcare provided by adults under conditions of food insecurity. J Rural Med. 2016;11(2):47-57.

41. Gaurav K, Poudel I, Bhattarai S, Pradhan P, Pokharel P. Malnutrition status among Under-5 children in a hill Community of Nepal. Kathmandu Univ Med J. 2014;12(4):264-8.

42. Juma OA, Enumah ZO, Wheatley H, Rafiq MY, Shekalaghe S, Ali A, et al. Prevalence and assessment of malnutrition among children attending the reproductive and child health clinic at Bagamoyo District hospital, Tanzania. BMC Public Health. 2016;16(1):1094.

43. Molla E, Mamo H. Soil-transmitted helminth infections, anemia and undernutrition among schoolchildren in Yirgacheffee, South Ethiopia. BMC Res Notes. 2018;11(1):585.

44. Hs J, Gupta R, Joshi M, Vipul M. Determinants of nutritional status of school children-a cross sectional study in the western region of Nepal. Njirm. 2011; 2(1):1-13.

45. Daboné C, Delisle HF, Receveur O. Poor nutritional status of schoolchildren in urban and peri-urban areas of Ouagadougou (Burkina Faso). Nutr J. 2011; 10(1):34

46. Agbozo F, Atitto P, Abubakari A. Nutritional status of pupils attending public schools with and without school feeding programme in Hohoe municipality GHANA; 2017.

47. Nokes C, Bundy DA. Does helminth infection affect mental processing and educational achievement? Parasitol Today (Personal ed). 1994;10(1):14-8.

48. Nokes C, Grantham-McGregor S, Sawyer A, Cooper E, Bundy D. Parasitic helminth infection and cognitive function in school children. Proc R Soc Lond Ser B Biol Sci. 1992;247(1319):77-81.

49. Nyaruhucha C, Mamiro P, Kerengi A, Shayo N. Nutritional status of underfive children in a pastoral community in Simanjiro District, Tanzania. Tanzan J Health Res. 2006;8(1):32-6.

50. Hadidjaja P, Bonang E, Suyardi MA, Abidin SA, Ismid IS, Margono SS. The effect of intervention methods on nutritional status and cognitive function of primary school children infected with Ascaris lumbricoides. Am J Trop Med Hyg. 1998;59(5):791-5.
51. Sonkaria L, Zafer A, Gaur KL, Manohar RK. Maternal factors associated with nutritional status of 1-5 years children residing in field practice area of rural health training Centre Naila, Jaipur (Rajasthan) India. Natl J Community Med. 2014:5(3):283-7.

52. Getaneh Z, Enawgaw B, Engidaye G, Seyoum M, Berhane M, Abebe Z, et al. Prevalence of anemia and associated factors among school children in Gondar town public primary schools, Northwest Ethiopia: a school-based cross-sectional study. PLoS One. 2017;12(12):e0190151.

53. Alelign T, Degarege A, Erko B. Prevalence and factors associated with undernutrition and anaemia among school children in Durbete town, Northwest Ethiopia. Arch Public Health. 2015;73(1):34

54. Feleke BE. Nutritional status and intestinal parasite in school age children: a comparative cross-sectional study. Int J Pediatr. 2016;2016.

\section{Publisher's Note}

Springer Nature remains neutral with regard to jurisdictional claims in published maps and institutional affiliations.

Ready to submit your research? Choose BMC and benefit from:

- fast, convenient online submission

- thorough peer review by experienced researchers in your field

- rapid publication on acceptance

- support for research data, including large and complex data types

- gold Open Access which fosters wider collaboration and increased citations

- maximum visibility for your research: over $100 \mathrm{M}$ website views per year

At BMC, research is always in progress.

Learn more biomedcentral.com/submissions 